\title{
GM2/GD2/GD3 Lactone-KLH Conjugate Trivalent Vaccine
}

National Cancer Institute

\section{Source}

National Cancer Institute. GM2/GD2/GD3 Lactone-KLH Conjugate Trivalent Vaccine. NCI

Thesaurus. Code C91377.

A trivalent cancer vaccine containing the gang lioside lactones GM2, GD2 and GD3

conjug ated with the immunostimulant keyhole limpet hemocyanin $(\mathrm{KLH})$, with potential antineoplastic activity. Vaccination with GM2 lactone/GD2 lactone/GD3 lactone-KLH conjug ate trivalent vaccine may elicit antibodies against tumor cells expressing any of these epitopes, resulting in an antibody-dependent cell-mediated cytotoxicity (ADCC) against tumor cells expressing these gang liosides. GM2, GD2 and GD3 are tumor associated antigens (TAAs) that are overexpressed in a variety of tumor cell membranes. 